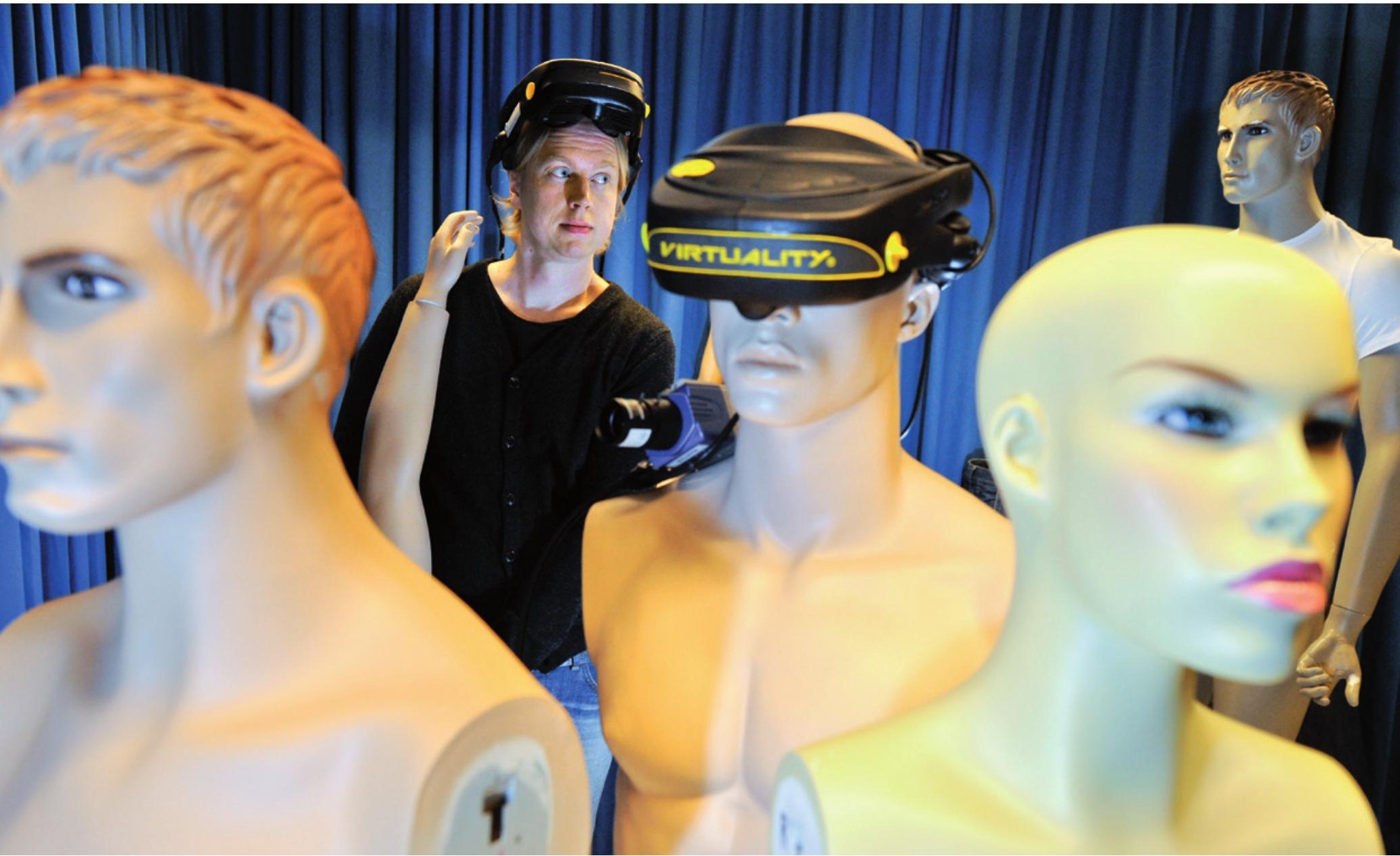

\title{
Master of illusion
}

\section{Henrik Ehrsson uses mannequins, rubber arms and virtual reality to create body illusions, all in the name of neuroscience.}

\author{
BY ED YONG
}

$\mathrm{I}$ $t$ is not every day that you are separated from your body and then stabbed in the chest with a kitchen knife.

But such experiences are routine in the lab of Henrik Ehrsson, a neuroscientist at the Karolinska Institute in Stockholm, who uses illusions to probe, stretch and displace people's sense of self. Today, using little more than a video camera, goggles and two sticks, he has convinced me that I am floating a few metres behind my own body. As I see a knife plunging towards my virtual chest, I flinch. Two electrodes on my fingers record the sweat that automatically erupts on my skin, and a nearby laptop plots my spiking fear on a graph.

Out-of-body experiences are just part of
Ehrsson's repertoire. He has convinced people that they have swapped bodies with another person $^{1}$, gained a third $\mathrm{arm}^{2}$, shrunk to the size of a doll or grown to giant proportions ${ }^{3}$. The storeroom in his lab is stuffed with mannequins of various sizes, disembodied dolls' heads, fake hands, cameras, knives and hammers. It looks like a serial killer's basement. "The other neuroscientists think we're a little crazy," Ehrsson admits.

But Ehrsson's unorthodox apparatus amount to more than cheap trickery. They are part of his quest to understand how people come to experience a sense of self, located within their own bodies. The feeling of body ownership is so ingrained that few people ever think about it - and those scientists and philosophers who do have assumed that it was unassailable.

"G. E. Moore said that if there's something you can be certain of in this world, it's that your hand is your hand," says Ehrsson. Yet Ehrsson's illusions have shown that such certainties, built on a lifetime of experience, can be disrupted with just ten seconds of visual and tactile deception. This surprising malleability suggests that the brain continuously constructs its feeling of body ownership using information from the senses - a finding that has earned Ehrsson publications in Science and other top journals, along with the attention of other neuroscientists.

"A lot of people thought the sense of self 
was hard-wired, but it's not at all. It can be changed very quickly, and that's very intriguing," says Miguel Nicolelis, a neurobiologist at Duke University Medical Center in Durham, North Carolina.

Ehrsson's work also intrigues neuroscientists and philosophers because it turns a slippery, metaphysical construct - the self - into something that scientists can dissect. "We can say if we wobble the signals this way, our conscious experience wobbles in this way," says David Eagleman, a neuroscientist who studies perception at Baylor College of Medicine in Houston, Texas. "That's a lever we didn't have before."

"There are things like selfhood that people think cannot be touched by the hard sciences," says Thomas Metzinger, director of the Theoretical Philosophy Group at Johannes Gutenberg University of Mainz, Germany. "They are now demonstrably tractable. That's what I think is valuable about Henrik's contribution."

\section{DAYDREAM BELIEVER}

Ehrsson was born in 1972 in a suburb of Stockholm. His father was a chemist, his grandfather a dentist, and both stoked an interest in science and the human body that led him to study medicine at the Karolinska Institute. But in long anatomy classes, Ehrsson often found himself bored. "During lectures, I kept on thinking that if my eyes were floating over there and I was looking at myself from that perspective, where would my consciousness be?" After a pause:

"I was not an A student."

After graduating, Ehrsson left medicine to start a $\mathrm{PhD}$ at the Karolinska, using brain scanners to study how people grasp objects. At the same time, he was becoming deeply fascinated by physical illusions. Some of these are well established: Aristotle discovered that crossing the index and middle fingers and touching the nose can - in some people - create a feeling of having two noses. Ehrsson also heard about the rubber-hand illusion, a trick devised in the late 1990s by researchers in the United States. They could convince people that a fake hand was their own by hiding their real hand under a table, placing a rubber one in front of them, and stroking both in the same way ${ }^{4}$. "It really worked on me," Ehrsson says. "It was fantastic and surreal."

Ehrsson started investigating illusions on the side. By the time he completed his postdoc at University College London and returned to the Karolinska Institute to start his own lab, illusions had become his main focus. $\mathrm{He}$ knew that many scientists use visual illusions to glean the basics of perception. "There are conferences on visual illusions, and yearly contests to create the best new ones," he says. "But there aren't many body illusions. The body has never been a main focus of psychology." It was these tricks, such as the rubber-hand illusion, that Ehrsson was keen to explore. He wanted to test how easily the sense of body ownership could be distorted.

Ehrsson set about creating more illusions based on the same principles as the rubber hand one. Headsets, cameras or fake body parts fooled the eyes, and synchronous strokes and prods added a tactile clincher. In 2007, he reported that he had used such props to convince subjects that they had left their own bodies $^{5}$ - a stunt that attracted headlines around the world.

At the time, some scientists and members of the public were openly sceptical that the illusion really worked. But on a trip to Ehrsson's lab this September, I was convinced. The goggles I wore displayed the view from a camera pointing at my back (see 'Out-of-body experience'). Ehrsson tapped my chest with one plastic rod while using a second one to synchronously prod at the camera. I saw and felt my chest being prodded at the same time as I saw a picture of myself from behind. Within ten seconds, I felt as if I was being pulled out of my real body
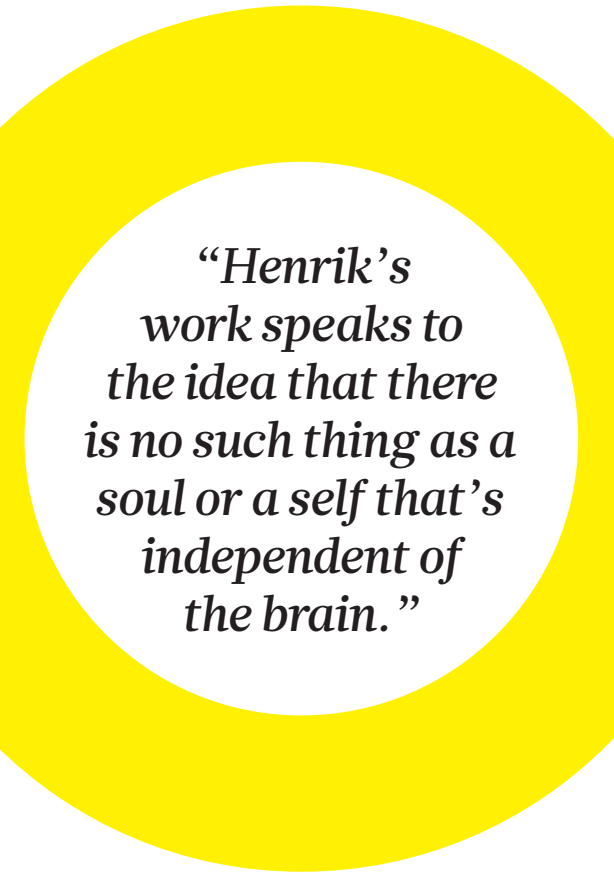

and was floating several feet behind it.

A year after removing his subjects from their own bodies, Ehrsson learned how to trick them into acquiring new ones. This time, the volunteers' goggles showed them the view from a camera on the head of a mannequin looking at its own plastic torso. Simultaneously poking the arm or stomach of the mannequin and the volunteer a few times was enough to convince the subjects that they were the dummy. They could even stare at their old bodies from their new ones and shake hands with their old self, all without breaking the spell ${ }^{1}$. "It really is very intense and incredibly fast," says Mark Hallett, a neurologist from the National Institutes of Health in Bethesda, Maryland, who experienced it first hand.

In his latest trick, published in $\mathrm{May}^{3}$, Ehrsson convinced people that they had jumped into a tiny Barbie doll. When he prodded the doll's legs, the volunteers thought they were being prodded by giant objects. And when Ehrsson tested the illusion on himself and a colleague touched his cheek, he says, he looked up and "felt as if I was back in my childhood and looking at my mother".

Not everyone succumbs. Ehrsson suspects that people who can expertly localize their limbs without sight, such as dancers or musicians, would be less susceptible than the students with whom he normally works. But typically, the illusions work for around four out of five people. Ehrsson confirms the effects by asking his volunteers about their experiences and by threatening their disembodied, shrunken or plastic forms with a knife. If the illusion has worked, then volunteers show a reflexive burst of nervous sweating (as I did). Even knowing the knife is coming is no defence: as Ehrsson puts it, the illusions are "cognitively impregnable".

Earlier this year, Ehrsson even tweaked the rubber-hand illusion and convinced people

they owned a third hand" . "He has taken those basic ideas and investigated how far you can push them," says neuroscientist Matthew Botvinick, one of the creators of the rubber-hand illusion, at Princeton University in New Jersey. "He's shown how extreme and how malleable the body representation can be."

\section{SELF DELUSION}

Ehrsson's next challenge is to work out what these illusions reveal about the brain. According to textbook wisdom, people build up a perception of their bodies using 'proprioception' - signals from the skin, muscles and joints that indicate the relative position of body

parts. But Ehrsson's illusions show that vision and touch are also a crucial part of the mix, and that the brain builds a sense of self by constantly compiling information from all these senses. Proprioception may be telling the brain that the body is seated in a chair, but the carefully timed vision and touch signals in Ehrsson's illusion convince the brain that it is somewhere else entirely.

Ehrsson thinks such illusions depend on 'multisensory' neurons, which have been studied mostly in monkeys and allow the animals to successfully interact with objects by combining vision and touch. "We think these circuits are important, not just for representing external objects," says Ehrsson, "but representing your own body and the boundary between your body and the world." He thinks that the 


\section{OUT-OF-BODY EXPERIENCE}

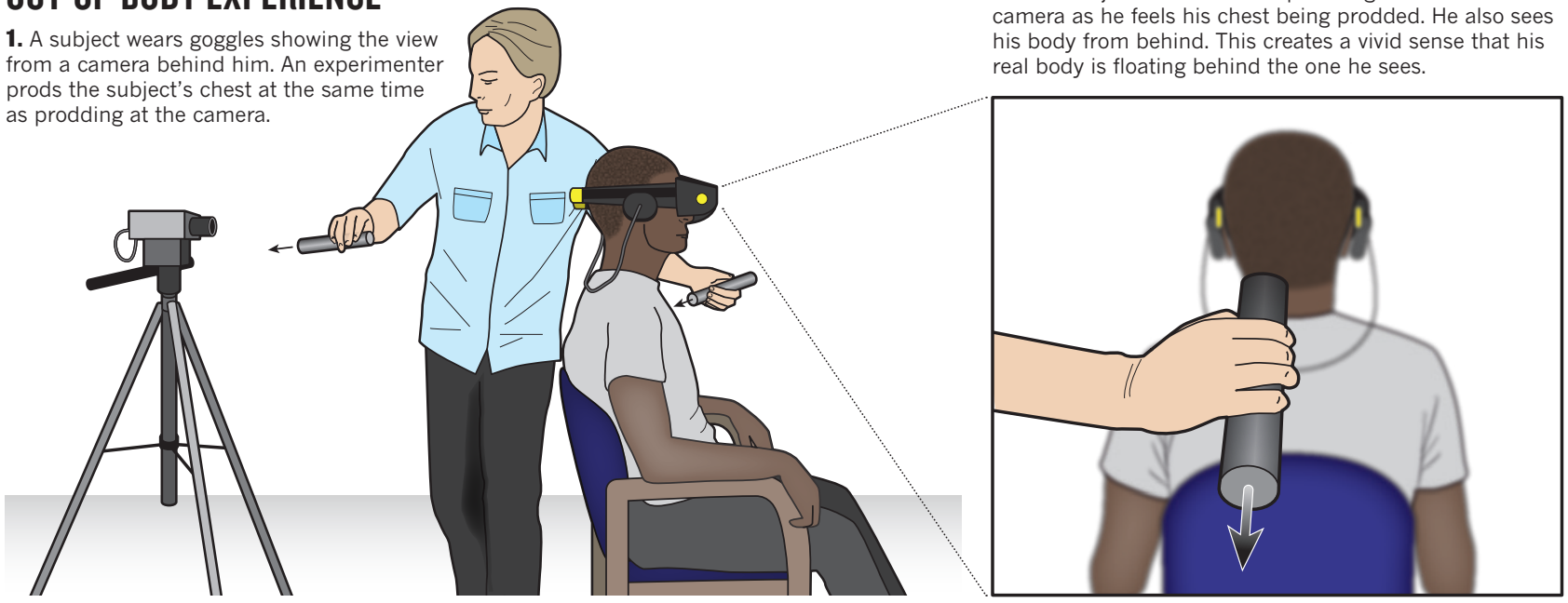

2. The subject sees the hand prodding towards the . real body is floating behind the one he sees. neurons integrate information from across the senses to create a cohesive representation of the body. During an illusion, he simply changes the data flooding into the neurons to manipulate that representation.

For now, this is a working hypothesis. "The details of the multisensory integration have never been formally worked out," says Botvinick. "That's the missing link for me." Ehrsson and others are busy trying to see where these multisensory neurons reside in the human brain, by inducing illusions while volunteers sit inside a functional magnetic resonance imaging machine. The results differ. Ehrsson has found that the ventral premotor cortex - known to be involved in visual guidance of movements - is particularly active when people experience the full body-swap illusion $^{6}$. Olaf Blanke at the University of Lausanne in Switzerland, one of only a handful of other researchers in this field, has shown that the nearby temporoparietal junction lights up when people experience out-of-body illusions ${ }^{7}$. He points out that brain damage or tumours in that area can induce disembodied feelings. "It's difficult to judge which is right, because we just have a thin neuroscientific layer of data at the moment," says Blanke.

\section{SOUL SEARCHING}

Ehrsson's interests in the self and body ownership bleed into the rest of his life. He is drawn towards experimental theatre and surrealist art. He comes across as thoughtful and remote, easily forgetting the names of colleagues and often lapsing into silence. He prefers working in his lab to going to conferences, he says.

He also occasionally gets angry letters from people who have had out-of-body experiences themselves. "They believe that their souls have left their bodies, and they feel threatened that a similar experience can be induced in a lab," says Ehrsson. He offers a diplomatic response,

saying that he has "no way of disproving their ideas". Metzinger is more forthright. "Henrik's work speaks to the idea that there is no such thing as a soul or a self that's independent of the brain," he says.

Ehrsson is now working to turn his illusions towards a practical goal: developing better artificial limbs. Many people who have lost arms still feel the presence of their missing limbs, yet replacement hands feel alien. "We think that people might find it easier to use their prostheses, or develop a better body image, if we can elicit the illusion of real ownership," says Ehrsson.

To achieve this, he has adapted the rubberhand illusion. With amputees, Ehrsson stimulates small spots on the stump that trigger the feeling of phantom fingers. By stroking these spots in time with the corresponding parts of a robotic 'cyberhand', Ehrsson and his colleagues have successfully convinced amputees that they owned the metal limb ${ }^{8}$.

The effect disappeared about 10 to $15 \mathrm{sec}$ onds after the stroking stopped, though, so the stimulation would have to be continuous to keep the illusion going. That is what Ehrsson is working towards now. "The idea is to have an advanced prosthetic hand with sensors in the fingertips and stimulators in the stump," he says. Although other groups are working on similar sensory devices, Ehrsson says that his is different because he is attempting to precisely match up the feelings from the artificial fingers with stimulation in the corresponding part of the stump to generate the illusion of ownership.

Ehrsson has even bigger ambitions. Ownership illusions could help people to take

\section{DNATURE.COM}

For a podcast on the out-of-body illusion, see:

go.nature.com/9bbm4g the joysticks and other controllers used to steer robots and avatars today. People who control robots, for example, would see from their machine's perspective using goggles, steer using motion-capture suits and receive tactile feedback from gloves connected to sensors in the robot's hands. As long as signals are transferred between human and machine within 100 milliseconds, Ehrsson predicts that "the full-body illusion will kick in". And size should not matter. A surgeon could control a microscopic robot in a patient's body. Giant robots could repair broken oil rigs or fractured nuclear power stations. Ehrsson smiles as he considers the possibilities.

There is one illusion that even Ehrsson is unsure if he can pull off: splitting the sense of self, so that a person can commandeer two bodies. Ehrsson thinks that the trick's feasibility may depend on how the brain integrates information from the senses. "Maybe it's statistical in nature. Maybe instead of using absolute coordinates, the brain says it's most likely that my hand is here," he says. "If it works like that, maybe you could trick the brain into thinking that this body and that body are equally likely to be me."

It sounds far-fetched, but so does most of what Ehrsson has achieved so far. "We're working on it," he says. "Then again, it might be impossible."

Ed Yong is a freelance writer based in London who writes the blog 'Not Exactly Rocket Science?

1. Petkova, V. I. \& Ehrsson, H. H. PLoS ONE 3, e3832 (2008).

2. Guterstam, A., Petkova, V. I. \& Ehrsson, H. H. PLoS ONE 6, e17208 (2011).

3. van der Hoort, B., Guterstam, A. \& Ehrsson, H. H. PLOS ONE 6, e20195 (2011)

4. Botvinick, M. \& Cohen, J. Nature 391, 756 (1998)

5. Ehrsson, H. H. Science 317, 1048 (2007)

6. Petkova, V. I. et al. Curr. Biol. 21, 1118-1122 (2011)

7. Ionta, S. et al. Neuron 70, 363-374 (2011).

8. Rosen, B. et al. Scand. J. Plast. Recons. http://dx.doi. org/10.1080/02844310903113107 (2009). 